\title{
Mitochondrial function and dysfunction in sepsis
}

\author{
Martina Wendel ${ }^{1}$ and Axel R. Heller ${ }^{2}$ \\ ${ }^{1}$ Fachklinik Prinzregent Luitpold, Scheidegg, Germany \\ ${ }^{2}$ Medical Faculty Carl-Gustav-Carus, Department of Anesthesiology and Critical Care Medicine, \\ University of Technology, Dresden, Germany
}

\section{Mitochondriale Funktion und Dysfunktion bei der Sepsis}

Zusammenfassung. Die Mitochondrien sind die quantitative bedeutsamste ATP-Quelle von Zellen. Durch die pathophysiologischen Vorgänge, die im Verlauf der Abwehr von eindringenden Miroorganismen in Gang gesetzt werden, kommt es zu einer Beeinrächtigung von Funktion und Struktur der Mitochondrien. Insbesondere das hochreaktive Peroxynitrit, das aus der Reaktion von Stickstoffmonoxid und Superoxid-Anionen entsteht, schädigt die mitochondrialen Lipide, Proteine und Nukleinsäuren.

Der starke oxidative Stress induziert DNA-Strangbrüche, die unter Aktivierung der Poly(ADP-Ribose)-Polymerase repariert werden. Dieser Prozess verbraucht große Mengen an Nicotinamid-Dinucleotid $\left(\mathrm{NAD}^{+}\right)$, wodurch es zur zellulären $\mathrm{NAD}^{+}$-Verarmung kommt. Dies beeinträchtigt die Einschleusung von Elektronen in die Atmungskette und verstärkt die Inflammation.

Neue therapeutische Strategien, die auf eine Abschwächung der Wirtsreaktion auf eindringende Mikroorganismen oder auf eine Modulation intrazellulärer Signalkaskaden, die zu oxidativem Stress führen, abzielen, konnten in experimentellen Studien die mitochondriale Funktion und letztlich auch die Organfunktion verbessern.

Schlüsselwörter: Sepsis, Mitochondrien, Zytokine, reaktive Sauerstoffspezies, reaktive Stickstoffspezies

Summary. Mitochondria are the key source of cellular ATP and their structure and function are markedly affected by pathophysiologic processes associated with the host's response to invading pathogens. In particular, the highly reactive compound peroxynitrite, generated by the reaction of nitric oxide and superoxide anions, inhibits mitochondrial enzymes and damages lipids, proteins, and nucleic acids.

Enhanced oxidative stress induces DNA strand breaks that are repaired by activation of poly(ADP-ribose)polymerase (PARP). This process consumes large amounts of nicotinamide adenine dinucleotide $\left(\mathrm{NAD}^{+}\right)$leading to cellular $\mathrm{NAD}^{+}$depletion that

Correspondence: Martina Wendel, M.D., Fachklinik Prinzregent Luitpold, Oberschwenden 70, 88175 Scheidegg, Germany. Fax: ++49-8381-896 1101, E-mail: MartinaWendel@gmx.de impairs flux of reducing equivalents into the respiratory chain and also further promotes inflammation.

In experimental studies, novel therapeutic strategies that aim to ameliorate the host's pathogen response or to modulate intracellular signaling events related to oxidative stress protected mitochondrial function and preserved cellular respiration ultimately leading to improved organ function.

Key words: Sepsis, mitochondria, cytokines, reactive oxygen species, nitric oxide, reactive nitrogen species

\section{Introduction}

Organ dysfunction occurring in the course of severe sepsis and septic shock has long been considered as the consequence of impaired oxygen availability due to macro- and microcirculatory hemodynamic disturbances. However, in the last decade, the concept of mitochondrial dysfunction associated with the production of pro-inflammatory mediators during the host's response to invading microorganisms has gained more and more attention. In the meantime, it is widely accepted that the impairment of mitochondrial function significantly contributes to organ failure in septic patients. However, in the clinical setting approaches to improve diagnosis and install more efficient treatment modalities are still lacking.

In this article, the basic mechanisms of mitochondrial function and dysfunction during sepsis will be summarized and emerging diagnostic and therapeutic tools in the field will be discussed.

\section{Physiology of mitochondria}

The enzyme complexes of the respiratory chain The respiratory chain is the major site of cellular ATP production with its enzyme complexes being located at 


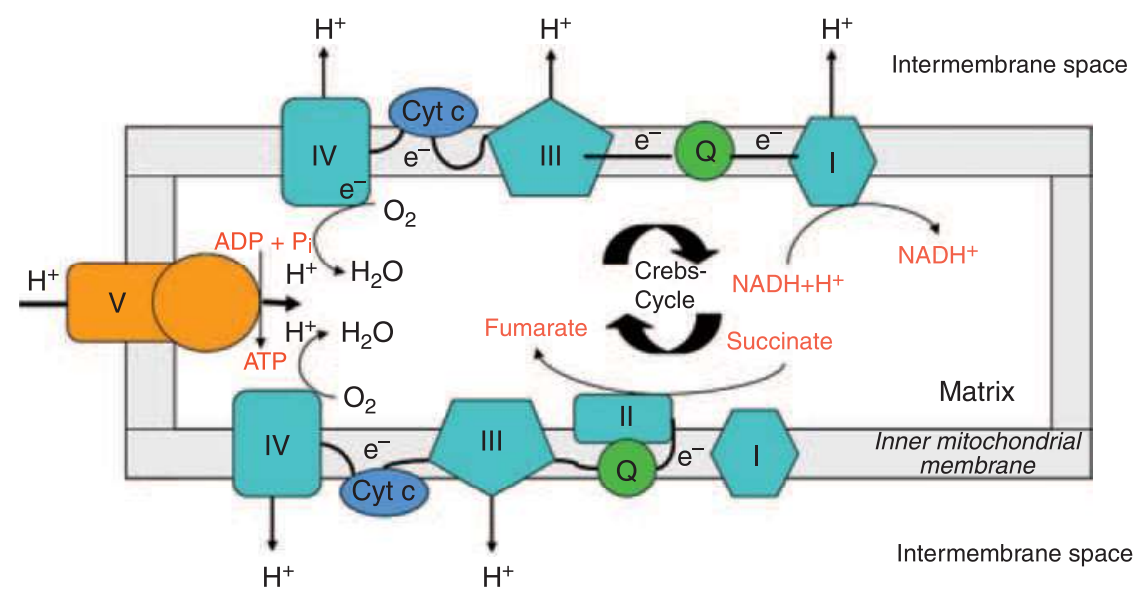

Fig. 1: Scheme of the enzyme complexes of the respiratory chain located at the inner mitochondrial membrane. Reducing equivalents can enter either at complex I $\left(\mathrm{NADH}+\mathrm{H}^{+}\right)$or at complex II $\left(\mathrm{FADH}_{2}\right)$. Q: Ubichinone, $\mathrm{e}^{-}$: electrons, $\mathrm{H}^{+}$: protons

the inner membrane of the mitochondria (Fig. 1). The reducing equivalents $\mathrm{NADH}+\mathrm{H}^{+}$and $\mathrm{FADH}_{2}$ obtained during the breakdown reactions of glucose, amino acids, and lipids are introduced into the respiratory chain. Via stepwise redox reactions, their electrons are transferred along the enzyme complexes of the respiratory chain and ultimately lead to the reduction of molecular oxygen. While $\mathrm{NADH}+\mathrm{H}^{+}$enters at complex $\mathrm{I}$, the NADH:oxidoreductase, $\mathrm{FADH}_{2}$ is introduced via the succinat:ubichinone-oxidoreductase located in complex II. Via both pathways, the electrons are then transferred to ubichinone which is reduced to ubihydrochinone. In addition, at complex I four protons are pumped from the mitochondrial matrix into the intermembrane space in parallel with the electron transfer. In complex III, which consists of a ubihydrochinone: cytochrome c oxidase, ubihydrochinone is oxidized and cytochrome c is reduced. Simultaneously, two protons are pumped into the intermembrane space. In complex $\mathrm{IV}$, at the cytochrome $\mathrm{c}: \mathrm{O}_{2}$ oxidoreductase, cytochrome c becomes oxidized again and after transfer of four electrons, one unbound molecule of oxygen can react with four protons derived from the mitochondrial matrix to form two molecules of water. The energy that is liberated during this reaction then serves to pump further four protons from the mitochondrial matrix into the intermembrane space. At complex V, which contains the ATP-synthetase, the proton gradient that was established during the previous steps serves as a driving force for the generation of ATP from ADP and phosphate.

\section{Mitochondrial ROS}

Physiologically, small amounts of reactive oxygen species are produced at complexes I and III of the respiratory chain (Fig. 2). Superoxide anions are dismutated to $\mathrm{H}_{2} \mathrm{O}_{2}$ by manganese superoxide dismutase (Mn-SOD). In the presence of reduced glutathione (GSH) $\mathrm{H}_{2} \mathrm{O}_{2}$ is further catalyzed to water by GSH-peroxidases.

\section{Mitochondrial DNA}

The mitochondrial genome encodes 13 proteins of the respiratory chain while all other mitochondrial proteins are encoded by the nuclear DNA. Furthermore,

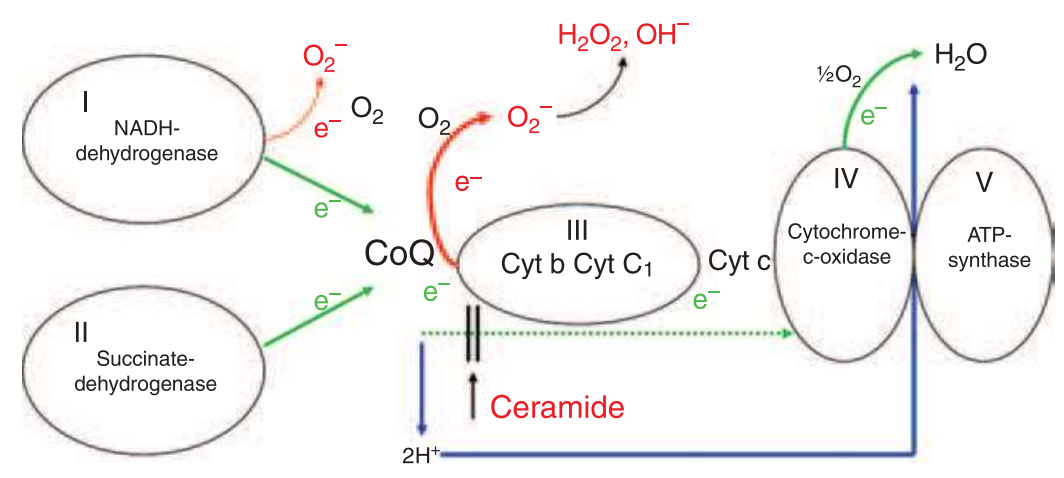

Fig. 2: Physiologically, small amounts of reactive oxygen species (ROS) are generated at complexes I and III. TNF- $\alpha$ causes increased ROS-production at complex III through ceramide-dependent inhibition of the respiratory chain 
replication of the mitochondrial DNA (mt DNA) is reglutated by nuclear transcription factors [1]. Special features of the mt DNA are its close proximity to ROS that are produced by the electron transfer reactions and the lacking of protecting histone proteins that make the mt DNA more susceptible to damaging agents. In addition, the copy number of the mt DNA is low.

\section{Oxidative stress in sepsis}

Sepsis is accompanied by increased oxidative stress [2]. A main source of ROS are activated neutrophils. Furthermore, xanthine oxidase activity in plasma and levels of nitric oxide as well as its reaction products nitrite and nitrate are increased. In serum, the antioxidative capacity is decreased (reduced levels of uric acid, unconjugated bilirubin, sulfhydryl groups of proteins, vitamins $\mathrm{C}$ and $\mathrm{E}$ and other still unknown factors), whereas the concentrations of lipid peroxides, nitrotyrosine, and thiobarbituric acid reactive substances, are increased.

Intracellularly, levels of GSH drop while the concentration of oxidized glutathione dimmers (GSSG) increase leading to a fall in the ratio of GSH/GSSG. While after an initial decrease in GSH inflammatory mediators induce an up-regulation of GSH-production, the levels of GSH decrease again during prolonged sepsis [3].

\section{Functional alterations of mitochondria during sepsis}

A large number of experimental studies demonstrated that pro-inflammatory mediators as well as oxidative stress directly impair the function of the enzyme complexes of the respiratory chain and cause structural damage to mitochondrial lipids, proteins and DNA $[4,5]$ thereby impairing cellular ATP production.

Besides broad data from animal experimental studies, also clinical data are available that show clear correlations between the degree of impairment of mitochondrial function and mortality [6].

Excessive production of nitric oxide and enhanced generation of ROS occur downstream of Toll-like receptor (TLR) activation. TNF- $\alpha$ inhibits the respiratory chain at the level of complex III in a ceramide-dependent manner (see Fig. 2) and leads to enhanced production of ROS [7]. The latter is further promoted when the mitochondrial antioxidative capacity is reduced leading to enhanced mitochondrial damage.
Large amounts of NO are produced by the inducible nitric oxide synthase (iNOS) that is transcriptionally activated by pro-inflammatory mediators. NO inhibits complex IV (this inhibition is reversible and can be overcome by high concentrations of oxygen), and this functional block enhances ROS production. Together with increased amounts of NO, superoxide anions form the highly reactive peroxynitrite the causes irreversible damage to proteins, lipids, and nucleic acids.

Structural alterations of mitochondria, as swelling, disruption of cristae, condensation, and elongation were found in intestinal epithelial cells, hepatocytes, and cardiomyocytes from septic animals [8-11]. Furthermore, in two clinical studies comparable changes were observed in tissue specimens obtained from patients not surviving septic shock [12, 13].

Once structural mitochondrial damage is established recovery of mitochondrial function depends on mitochondrial biogenesis [5].

\section{Mitochondrial dysfunction and septic cardiomyopathy}

In cardiomyocytes, there is good evidence that proinflammatory signaling events downstream of LPS binding to TLR4 lead to iNOS activation and subsequently reduce myocardial contractility and, at the single cell level, sarcomere shortening [14, 15]. Increased amounts of NO impaired myocardial contractility at an early time point $(6 \mathrm{~h})$ by NO-mediated activation of soluble guanylat cyclase (sGC). However, after $48 \mathrm{~h}$, inhibition of respiratory chain complexes I, II, and V was evident that could only be prevented by pre-treatment with the iNOS inhibitor aminoguanidine while an sGC inhibitor was without effect [10]. In addition to these observations, in a model of abdominal peritonitis, Larche showed irreversible inhibition of enzyme complex IV (cytochrome c oxidase), reduced content of cytochrome c oxidase, and also cellular cytochrome c depletion [16]. Interestingly, in this study, intravenous administration of cytochrome c refilled mitochondrial cytochrome c content and in parallel also restored myocardial contractility. Also opening of the mitochondrial permeability transition pore (MPTP) seems to contribute to septic cardiomyopathy as MPTP inhibition preserved myocardial contractility [17].

\section{Mitochondrial dysfunction of hepatocytes}

In hepatocytes, TNF- $\alpha$ exerted a direct inhibiting effect on mitochondrial function that was evident $2 \mathrm{~h}$ after incubation with the cytokine [18]. At later time points, 
models using either LPS or inducing abdominal sepsis delineated a clear role for NO in mitochondrial dysfunction and reduced cellular ATP generation [9, 19]. In parallel with decreased ATP production, also the ketone body ratio (KBR) which is directly proportional to the mitochondrial ratio of $\mathrm{NAD}^{+}$to $\mathrm{NADH}+\mathrm{H}^{+}$declined, and this could be reverted by the NOS inhibitor L-NMMA. Interestingly, a clinical study also demonstrated a correlation between increased plasma nitrate/ nitrite levels and reduced KBR in patients who died from sepsis [20].

\section{Mitochondrial dysfunction of intestinal epithelial cells} In intestinal epithelial cells, a cytokine mix (TNF- $\alpha$, IL$1 \beta$, and IFN- $\gamma$ ) induced an increase in anerobic glycolysis and ATP-turnover while cellular $\mathrm{NAD}^{+}$and $\mathrm{NADH}+\mathrm{H}^{+}$content decreased. Interestingly, cytomix incubation under hypoxic conditions further augmented these effects $[21,22]$. The authors further showed that the increased ATP-turnover was due to enhanced synthesis of proteins and nucleic acids. Scavengers of superoxide anions and nitric oxide and a compound that accelerates the decay of peroxynitrite were effective in preventing the decline in cellular oxygen utilization as was an inhibitor of poly(ADP-ribose)polymerase, an enzyme involved in DNA-repair mechanisms.

Activation of PARP has been shown to be proinflammatory by itself. Furthermore, it consumes large amounts of $\mathrm{NAD}^{+}$not available any more for catabolic redox reactions. In cytomix stimulated enterocytes, repletion with liposomal $\mathrm{NAD}^{+}$not only restored oxidative phosphorylation but also attenuated activation of NF- $\kappa \mathrm{B}$, iNOS and subsequent NO production. Furthermore, it reduced intestinal epithelial barrier dysfunction [22].

From these observations several central aspects of the pathophysiology of organ dysfunction related to mitochondrial dysfunction emerge that are summarized in Figs. 1, 3.

\section{Therapeutic strategies}

\section{Attenuation of oxidative stress}

As increased oxidative stress in the mitochondrial compartment caused by NO, ROS and peroxynitrite, seems to be causative for mitochondrial dysfunction, new specific antioxidants were developed that accumulate in mitochondria. Among these are the peptide antioxidants SS-31, which could restore myocardial contractility after ischemia/reperfusion inury [23], and the compound XJB-5-131. The antioxidative part of
XJB-5-131 consists of a nitroxide radical which by accepting an electron becomes reduced to a hydroxylamine and then serves as a scavenger for ROS. Hydroxylamines exhibit superoxide dismutase activity thereby preventing the reaction of superoxide anions with NO and subsequent generation of peroxynitrite. The mitochondrial targeting is accomplished by conjugation with a fragment of gramicidin S, a cell-membrane active antibiotic compound. XJB-5-131 improved intestinal barrier function and prolonged survival of rats after hemorrhagic shock. Furthermore, it reduced the activation of iNOS and consecutive NOproduction in mice $24 \mathrm{~h}$ after intraperitoneal LPS administration [24].

Also, selective inhibition of iNOS exhibited protective effects in animal experimental models of sepsis and improved both organ function and survival $[25,26]$. In contrast, non-selective inhibition of NOS showed conflicting results in different animal experimental studies, and even worsened outcome in the clinical setting so that a phase-III clinical trial was prematurely stopped [27].

\section{Attenuation of pro-inflammatory activation}

Inhibition of the DNA-repair enzyme PARP not only restored the oxygen utilization of enterocytes but also improved survival in animal models of sepsis and endotoxemia [28]. However, due to the high importance of genomic stability and potential consequences of PARPinhibition on tumorigenesis, caution should be taken concerning a potential application of PARP inhibitors in humans.

Beside PARP-inhibition, substitution of $\mathrm{NAD}^{+}$reduced the expression of pro-inflammatory mediators as mentioned above and may therefore be a therapeutic option.

At the level of modulating the host's immune response, HMGB1 has emerged as a new promising target molecule. HMGB1 is secreted by activated monocytes and is also liberated from necrotic cells. It binds to the receptor for advanced glycation end products, RAGE, and is also a ligand of TLR2 and 4. It reaches its secretion maximum at about $24 \mathrm{~h}$ and is able to perpetuate the immune cascade in the absence of the initiating stimulus.

Available antagonists are ethylpyruvate that prevents the secretion of HMGB1, and the so-called A-box fragment of HMGB1 that acts as an endogenous antagonist.

Their efficacy was demonstrated by a large number of animal experimental studies where they markedly reduced mortality from sepsis (for review see Ref. [29]). 


\section{Others}

Another approach to ameliorate mitochondrial dysfunction could be at the level of the choice of the energy substrate. Supplying succinate as energy substrate improved myocardial function after ischemia/reperfusion injury [30]. Furthermore, succinic acid dimethylester prevented the decline in hepatocyte ATP levels and improved survival in experimentally induced sepsis $[31,32]$.

In addition, there is evidence that the exogenous supply of cytochrome c can restore organ function as shown by improved myocardial function after infusion of cytochrome $\mathrm{c}$ in septic mice [16].

\section{Monitoring of organ function and tissue energetic states}

Monitoring tools to assess mitochondrial function and tissue energetic states for application in the clinical routine are still lacking.

Global parameters like central venous oxygen saturation, mean arterial pressure and urine production are very crude parameters to determine tissue perfusion and organ function. However, the use of more sophisticated techniques to assess the state of the microcirculation like sublingual and submucosal capnometry, orthogonal polarization spectroscopy and laser-doppler flowmetry have not yet established in clinical routine. The same holds true for near infrared spectroscopy that can determine the redox state of the cytochrome $\mathrm{aa}_{3}$ [33] and ${ }^{31} \mathrm{P}$ nuclear magnetic resonance technique [34] that allows the quantification of conversion rates of the energy rich phosphates. Both techniques are still restricted to the experimental setting.

So, in daily clinical practice we have to rely on the currently available guidelines for optimized treatment of septic patients with rapid hemodynamic stabilization and appropriate antibiotic treatment. The strategy of "early goal directed therapy" (EGDT) has first been established by Rivers and co-workers and implementation of the protocol significantly reduced the mortality of septic patients [35]. Interestingly, the time scale for efficient interventions according to these guidelines fits very well with the time course of the pathophysiologic alterations leading to mitochondrial dysfunction. Along with that, Rivers et al. could also demonstrate that their EGDT concept attenuated the expression of systemic markers of inflammation [36], so that it can be concluded that persistent hypotension with concomitant tissue ischemia and hypoxia amplifies and prolongs the in-

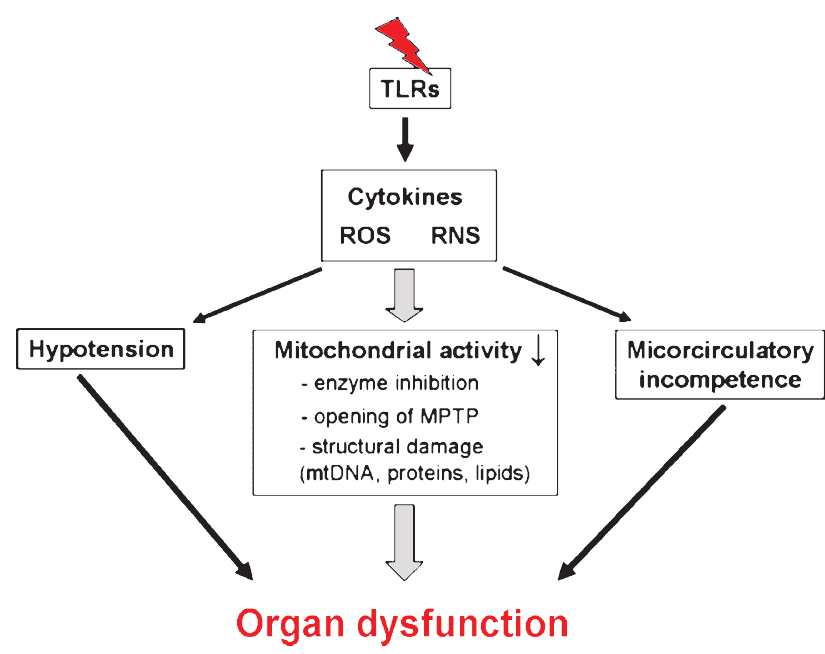

Fig. 3: Cytokines, nitric oxide, reactive oxygen species and reactive nitrogen species are induced in a Toll-like receptor dependent in response to invading pathogens. They cause mitochondrial dysfunction as well as macro- and microhemodynamic disturbances and ultimately leading to organ dysfunction

flammatory reaction associated with the host's response to invading pathogens and exaggerates mitochondrial functional and structural impairment. On the other hand, rapid hemodynamic stabilization (along with efficient antibiotic treatment) can interrupt this vicious circle (Fig. 3).

Hopefully, the recent insight into the pathophysiology of organ dysfunction elucidating the role of mitochondria will help to further improve diagnosis and monitoring of septic patients and will lead to more efficient treatment strategies to improve patients' survival.

\section{Conflict of interest}

The authors declare that there is no conflict of interest.

\section{References}

[1] Clayton DA. Transcription and replication of animal mitochondrial DNAs. Int Rev Cytol, 141: 217-232, 1992.

[2] Crimi E, Sica V, Williams-Ignarro S, et al. The role of oxidative stress in adult critical care. Free Radic Biol Med, 40: 398-406, 2006.

[3] Biolo G, Antonione R, De Cicco M. Glutathione metabolism in sepsis. Crit Care Med, 35(Suppl.): S591-S595, 2007.

[4] Suliman HB, Carraway MS, Piantadosi CA. Postlipopolysaccharide oxidative damage of mitochondrial DNA. Am J Respir Crit Care Med, 167: 570-579, 2007.

[5] Suliman HB, Welty-Wolf KE, Carraway M, et al. Lipopolysaccharide induces oxidative cardiac mitochondrial damage and biogenesis. Cardiovasc Res, 64: 279-288, 2004.

[6] Svistunenko DA, Davies N, Brealey D, et al. Mitochondrial dysfunction in patients with severe sepsis: An EPR interrogation of individual respiratory chain components. Biochim Biopyhs Acta, 1757: 262-272, 2006.

[7] Garcia-Ruiz C, Colell A, Mari M, et al. Direct effect of ceramide on the mitochondrial electron transport chain leads to generation of reactive oxygen species. J Biol Chem, 272: 11369-11377, 1997. 
[8] Crouser ED, Julian MW, Dorinsky PM. Ileal $\mathrm{VO}_{2}-\mathrm{DO}_{2}$ alterations induced by endotoxin correlate with severity of mitochondrial injury. Am J Resp Crit Care Med, 160: 1347-1353, 1999.

[9] Crouser ED, Julian MW, Blaho DV, Pfeiffer DR. Endotoxin-induced mitochondrial damage correlates with impaired respiratory activity. Crit Care Med, 30: 276-284, 2002.

[10] Tatsumi T, Akashi K, Keira N, et al. Cytokine-induced nitric oxide inhibits mitochondrial energy production and induces myocardial dysfunction in endotoxin-treated rat hearts. J Mol Cell Cardiol, 37: 775-784, 2004.

[11] Welty-Wolf KE, Simonson SG, Huang YC, et al. Ultrastructural changes in skeletal muscle mitochondria in Gram-negative sepsis. Shock, 5: 378-384, 1996.

[12] Soriano FG, Nogueira AC, Caldini EG, et al. Potential role of poly(adenosine $5^{\prime}$-diphosphate-ribose) polymerase activation in the pathogenesis of myocardial dysfunction associated with septic shock. Crit Care Med, 34: 1073-1079, 2006.

[13] Vanhorebeek I, De Vos R, Mesotten D, et al. Protection of hepatocyte mitochondrial ultrastructure and function by strict blood glucose control with insulin in critically ill patients. Lancet, 365: 53-69, 2005.

[14] Baumgarten G, Knuefermann P, Schuhmacher G, et al. Toll-like receptor 4, nitric oxide, and myocardial depression in endotoxemia. Shock, 25: 43-49, 2006

[15] Nemoto S, Vallejo JG, Knuefermann P, et al. Escherichia coli LPSinduced LV dysfunction: role of Toll-like receptor- 4 in the adult heart. Am J Physiol Heart Circ Physiol, 282: H2316-H2323, 2002.

[16] Levy RJ, Deutschmann CS. Cytochrome c oxidase dysfunction in sepsis. Crit Care Med, 35(Suppl.): S468-S475, 2007.

[17] Larche J, Lancel S, Hassoun SM, Favory R, et al. Inhibition of mitochondrial permeability transition prevents sepsis-induced myocardial dysfunction and mortality. J Am Coll Cardiol, 48: 377-385, 2006.

[18] Kurose I, Miura S, Higuchi H, et al. Increased nitric oxide synthase activity as a cause of mitochondrial dysfunction in rat hepatocytes: roles of tumor necrosis factor alpha. Hepatology, 24: 1185-1192, 1996.

[19] Tu W, Satoi S, Zhang Z, et al. Hepatocellular dysfunction induced by nitric oxide production in hepatocytes isolated from rats with sepsis. Shock, 19: 373-377, 2003.

[20] Satoi S, Kamiyama Y, Kitade H, et al. Nitric oxide production and hepatic dysfunction in patients with postoperative sepsis. Clin Exp Pharmacol Physiol, 27: 197-201, 2000.

[21] Berg S, Sappington PL, Guzik LJ, et al. Proinflammatory cytokines increase the rate of glycolysis and adenosine- $5^{\prime}$-triphosphate turnover in cultured rat enterocytes. Crit Care Med, 31: 1203-1212, 2003.

[22] Khan AU, Delude RL, Han YH, et al. Liposomal NAD ${ }^{+}$consumption prevents diminished $\mathrm{O}_{2}$ consumption by immunostimulated
Caco-2 cells. Am J Physiol Lung Cell Mol Physiol, 282: L1082-L1091, 2002.

[23] Cho S, Szeto HH, Kim E, et al. A novel cell-permeable antioxidant peptide, SS31, attenuates ischemic brain injury by down-regulating CD36. J Biol Chem, 282: 4634-4642, 2007.

[24] Fink MP, Macias CA, Xiao J, et al. Hemigramicidin-TEMPO conjugates: Novel mitochondria-targeted antioxidants. Crit Care Med, 35(Suppl.): S461-S467, 2007.

[25] King CJ, Tytgat S, Delude RL, Fink MP. Ileal mucosal oxygen consumption is decreased in endotoxemic rats but is restored toward normal by treatment with aminoguanidine. Crit Care Med, 27: 2518-2524, 1999.

[26] Matejovic M, Krouzecky A, Martinkova V, et al. Selective inducible nitric oxide synthase inhibition during long-term hyperdynamic porcine bacteremia. Shock, 21: 458-465, 2004.

[27] Lopez A, Lorente JA, Steingrub J, et al. Multiple-center, randomized, placebo-controlled, double-blind study of the nitric oxide synthase inhibitor 546C88: effect on survival in patients with septic shock. Crit Care Med, 32: 21-30, 2004.

[28] Gerö D, Szabo C. Poly(ADP-ribose) polymerase: a new therapeutic target? Curr Opin Anaesthesiol, 21: 111-121, 2008.

[29] Wang H, Zhu S, Zhou R, et al. Therapeutic potential of HMGB1targeting agents in sepsis. Expert Rev Mol Med, 10: e32, 2008.

[30] Cairns CB, Ferroggiaro AA, Walther JM, et al. Post-ischemic administration of succinate reverses the impairment of oxidative phosphorylation after cardiac ischemia and reperfusion injury. Circulation, 96(9 Suppl.): II260-II265, 1997.

[31] Ferreira FL, Ladriere L, Vincent JL, Malaisse WJ. Prolongation of survival time by infusion of succinic acid dimethyl ester in a caecal liagtion and perforation model of sepsis. Horm Metab Res, 32: 335-336, 2000 .

[32] Malaisse WJ, Nadi AB, Ladriere L, Zhang TM. Protective effects of succinic acid dimethyl ester infusion in experimental endotoxemia. Nutrition, 13: 330-341, 1997.

[33] Schaefer CF, Lerner MR, Biber B. Dose-related reduction of intestinal cytochrome aa3 induced by endotoxin in rats. Circ Shock, 33: 17-25, 1991.

[34] Kobayashi A, Okayama Y, Yamazaki N. ${ }^{31}$ P-NMR magnetization transfer study of reperfused rat heart. Mol Cell Biochem, 119: 121-127, 1993.

[35] Rivers E, Nguyen B, Havstad S, et al. Early Goal-Directed Therapy Collaborative Group. Early goal-directed therapy in the treatment of severe sepsis and septic shock. New Engl J Med, 345: 1368-1377, 2001.

[36] Rivers EP, Kruse JA, Jacobsen G, et al. The influence of early hemodynamic optimization on biomarker patterns of severe sepsis and septic shock. Crit Care Med, 35: 2016-2024, 2007. 